\title{
A bifunctional catalyst based ECL immunosensor for a cardiac biomarker regulated by oxygen evolution reaction
}

Hongli Zheng ${ }^{\text {a }}$, Qingrong Zhang ${ }^{\text {a }}$, Zhensheng Hong ${ }^{b^{*}}$, Yanyu Lin ${ }^{c^{*}}$, Hong Dai ${ }^{{ }^{*}}$

a College of Chemistry and Chemical Engineering, Fujian Normal University, Fuzhou, Fujian, 350108,China

b Fujian Provincial Key Laboratory of Quantum Manipulation and New Energy Materials, College of Physics and Energy, Fujian Normal University, PR China

c Key Laboratory of Humid Subtropical Ecogeographical Process of the Ministry of Education, College of Geographical Science, Fujian Normal University, Fuzhou, Fujian, 350108,China

${ }^{1}$ Corresponding author: Fax: (+86)-591-22866135; E-mail: dhong@fjnu.edu.cn (H. Dai); linyanyu2248@163.com (Y. Lin) 


\section{Abstract}

Prostaglandin E1, a cardiac biomarker, is a pivotal member of the prostaglandin family which exerts diverse and powerful effects on cell function in many organ systems. In this study, a new approach for the ultrasensitive determination of prostaglandin E1 was proposed by using the ECL of peroxydisulfate with oxygen as coreactant. Compared to most peroxydisulfate ECL sensor, this proposed ECL strategy propounded employing oxygen evolution reaction to enhance the concentration of oxygen, which was unprecedented in ECL sensing platform. Herein, ultrathin $\mathrm{NiCo}_{2} \mathrm{O}_{4}$ nanosheets with large surface area and mesoporous structure were prepared by a facile method, and adamantane as enhancer was decorated on the surface of amino-modified $\mathrm{NiCo}_{2} \mathrm{O}_{4}$ to generate a bifunctional catalyst of $\mathrm{NiCo}_{2} \mathrm{O}_{4} @ \mathrm{AD}$, which possessed excellent catalytic performance toward the oxygen evolution reaction. Accordingly, the sensitivity of ECL immunosensor was enhanced with the increasing concentration of oxygen by the bifunctional catalyst of $\mathrm{NiCo}_{2} \mathrm{O}_{4} @ \mathrm{AD}$. And the ECL response of the peroxydisulfate would decrease owing to the interaction between antibody and antigen on the modified electrode. Consequently, on the basis of the ECL intensity change of peroxydisulfate, the proposed immunosensor has realized ultrasensitive PGE1 assay with a wide linear detection range of $0.1 \mathrm{fg} / \mathrm{ml}$ to $1 \mathrm{ng} / \mathrm{ml}$ and a detection limit of $0.1 \mathrm{fg} / \mathrm{ml}$. The proposed ECL immunosensor was performed to analyze prostaglandin E1 in human serum, and satisfactory recoveries were obtained, indicating its potential applications in clinical diagnostics. 
Keywords: Electrochemiluminescent immunosensor, Bifunctional catalyst, Dissolved oxygen, Oxygen evolution reaction. 


\section{Introduction}

Prostaglandin E1 (PGE1), is a pivotal member of the prostaglandin family which are cyclic, oxygenated fatty acids that exert diverse and powerful effects on cell function in many organ systems[1,2]. As a product of arachidonic acid metabolism by cyclooxygenase, PGE1 is associated with pro- and anti-inflammatory actions [2], osteoporosis, and some studies have found PGE1 could reduce the compression trauma-induced spinal cord injury and had beneficial effect on osteoporosis management[3, 4]. Additionally, PGE1, as a potent vasodilator, has beneficial hemodynamic effects on patients with severe heart failure by increasing cardiac output and decreasing filling pressures and pulmonary vascular resistance[5]. Considering that PGE1 is closely related to vascular disease and pulmonary disease, it is of vital importance to monitor and quantify the PGE1 levels in human body and an accurate and cost-effective method for the detection of PGE1 is in great demand.

Electrochemiluminescence (ECL) technique, a promising detection method, involves the advantage of both electrochemistry and chemiluminescence and thus can realize ultrasensitive assays for targets[6,7]. As a potential ECL reagent, peroxydisulfate $\left(\mathrm{S}_{2} \mathrm{O}_{8}{ }^{2-}\right)$ has attracted considerable attention due to its fascinating advantages of simplicity, cost-effective, availability and sensitivity, and it has been put forward to use in immunoassay with oxygen $\left(\mathrm{O}_{2}\right)$ as coreactant $[8,9]$. The increasing concentration of the $\mathrm{O}_{2}$ is an effective way to improve the sensitivity of ECL detection because that the concentration of the $\mathrm{O}_{2}$ largely influence the ECL signal of $\mathrm{S}_{2} \mathrm{O}_{8}{ }^{2-}$. Accordingly, there is inexhaustible motive force to explore the 
methods for increasing the concentration of the $\mathrm{O}_{2}$. Niu et al, have used bienzyme functionalized palladium nanoparticles as labels to in situ generate $\mathrm{O}_{2}$ [9]. Wang et al., have proposed using $\mathrm{C}_{60}-\mathrm{L}-$ cysteine as a co-reactant and mimic bi-enzyme catalysis to in situ generate $\mathrm{O}_{2}$ for the enhancement of ECL response[10]. Liu et al., claimed the RGO/PtPd could catalytic oxidation of $\mathrm{H}_{2} \mathrm{O}_{2}$ to form $\mathrm{O}_{2}$ which acted as the coreactant of $\mathrm{S}_{2} \mathrm{O}_{8}{ }^{2-}$, then greatly amplified the ECL signal[11]. However, both bi-enzyme and mimic bio-enzyme catalytic oxidation of $\mathrm{H}_{2} \mathrm{O}_{2}$ to yield $\mathrm{O}_{2}$ strongly limited the development of $\mathrm{S}_{2} \mathrm{O}_{8}{ }^{2-}$ ECL sensing matrix because that bio-enzyme suffers from the vulnerable of denaturation, high cost in preparation and the difficulty of purification. Furthermore, most sensors involved bio-enzyme and mimetic enzyme needed $\mathrm{H}_{2} \mathrm{O}_{2}$ participate, which made the system relatively complicated. Nevertheless, there have been no reports about $\mathrm{H}_{2} \mathrm{O}_{2}$-free or enzyme-free to generate $\mathrm{O}_{2}$ acting as coreactant of $\mathrm{S}_{2} \mathrm{O}_{8}{ }^{2-}$. Therefore, a $\mathrm{H}_{2} \mathrm{O}_{2}$-free and enzyme-free strategy was immediately need to develop to amplify the ECL signal on the basis of Oxygen evolution reaction (OER).

OER, an electrochemical oxidation process, converts $\mathrm{H}_{2} \mathrm{O}$ into $\mathrm{O}_{2}$, in which the $\mathrm{O}-\mathrm{H}$ bond break and $\mathrm{O}=\mathrm{O}$ bond form[12]. Hitherto, a great number of strategies have been endeavored to develop efficient and cost-effective catalysts for the OER[13]. Generally, transition metals with multiple valence state, such as $\mathrm{Co}_{3} \mathrm{O}_{4}, \mathrm{NiO}, \mathrm{Ni}(\mathrm{OH})_{2}$ and $\mathrm{NiCo}_{2} \mathrm{O}_{4}$, its hydroxides or oxides have been reported to possess electrocatalytic activities for the OER $[12,14,15]$. Among these transition metal hydroxides or oxides, $\mathrm{NiCo}_{2} \mathrm{O}_{4}$ possesses much better electrical conductivity and electrochemical activity compared with those of binary nickel oxides or cobalt oxide[16], because of the co-contribution of $\mathrm{Ni}^{2+} / \mathrm{Ni}^{3+}$ and $\mathrm{Co}^{2+} / \mathrm{Co}^{3+}$ redox couples which contributed to 
various redox reactions and improved the performance of $\mathrm{NiCo}_{2} \mathrm{O}_{4}[17]$. Furthermore, its intriguing properties such as environmental benignity, low-cost and excellent biocompatibility make $\mathrm{NiCo}_{2} \mathrm{O}_{4}$ emerge as a promising material for diverse applications including supercapacitors[18], electrocatalytic water splitters[19], lithium-ion batteries [20] and immunosensor[16]. It is well known that the electrochemical activity of electrode materials is closely related to their morphology and size. Therefore, it would be primarily necessary to develop facile and simple technologies to synthesize nanostructure materials with preferable morphology and size[21]. Herein, ultrathin $\mathrm{NiCO}_{2} \mathrm{O}_{4}$ nanosheets with large surface area and mesoporous structure were developed by a facile method, in which the ultrathin feature would facilitate the electrolyte ion and electron transport, the porous feature would largely increase the amount of electro-active sites and the large surface area would provide more active sites for the immobilization of biomolecules. Many effects have been devoted to develop new strategy in order to improve the durability and activity of transition metal-based catalysts, and the combination of spinel with other materials into hierarchical structure become predominate in the light of introducing composite materials which could enhance the properties of the initial pure, single phase catalyst [22-29]. And most reports have focused primarily on the bifunctional catalysts that inorganic nano-materials were employed as supports for dispersion of transition metal-based catalysts, while few studies have been reported about coupling the $\mathrm{NiCo}_{2} \mathrm{O}_{4}$ with organic moiety. Moreover, steric saturation and electron rich-ness, as two primary factors in controlling the reactivity and stability of catalyst systems, play major role in controlling key steps of the catalytic cycle, and optimise these features could massively increase the property of catalyst. Therefore, in consideration of these reasons, adamantane (AD) is the promising alternative [30]. $\mathrm{AD}$ is a highly 
symmetric tricyclic hydrocarbon with three fused chair-form cyclohexane rings in a diamond lattice structure, which possesses superior thermal stability, high decomposition temperatures, good mechanical strength [30], and excellent biocompatibility[31,32]. In addition, the desirable properties such as low cost, stereoelectronic properties, ready availability and relative ease of functionalisation make $\mathrm{AD}$ an ideal candidate for incorporation into catalyst design. The use of $\mathrm{AD}$ in organometallic catalysis is relatively commonplace and has shown a great deal of success across a number of reaction types, however there are few reports concerning at $\mathrm{AD}$ conjoining with the transition metal catalyzer $\mathrm{NiCo}_{2} \mathrm{O}_{4}$ [30-32]. And it is conceivable that using $\mathrm{AD}$ to functionalize $\mathrm{NiCo}_{2} \mathrm{O}_{4}$ can successfully achieve the improvement of catalytic activity as result, since $\mathrm{AD}$ would play crucial roles at various key stages of the catalytic cycle on account of its large steric bulk and electron-donating abilities. To date, no studies have been conducted concerning AD functionalized $\mathrm{NiCo}_{2} \mathrm{O}_{4}\left(\mathrm{NiCo}_{2} \mathrm{O}_{4} @ \mathrm{AD}\right)$ as bifunctional catalyst for OER to yield $\mathrm{O}_{2}$ which could serve as coreactant of $\mathrm{S}_{2} \mathrm{O}_{8}{ }^{2-}$ in ECL reactions.

Herein, a bifunctiomal catalyst based ECL immunosensor was developed for the detection of PGE1 regulated by OER process. Here, AD as an enhancer was decorated onto the surface of amino-modified $\mathrm{NiCO}_{2} \mathrm{O}_{4}$ via the amidation reaction between the amino of amino-modified $\mathrm{NiCo}_{2} \mathrm{O}_{4}$ and the carboxyl of 1-adamantanecarboxylic acid to generate a bifunctional catalyst of $\mathrm{NiCo}_{2} \mathrm{O}_{4} @ \mathrm{AD}$. The bifunctional catalyst, combining the merits of ultrathin $\mathrm{NiCo}_{2} \mathrm{O}_{4}$ nanosheets with high porosity and excellent electrical conductivity and the merits of $\mathrm{AD}$ with large steric bulk and electron-donating abilities, showed a remarkable catalytic activity toward OER and further enhanced the ECL intensity of $\mathrm{S}_{2} \mathrm{O}_{8}{ }^{2-}$ significantly with the generation of $\mathrm{O}_{2}$. 
Furthermore, the $\mathrm{NiCo}_{2} \mathrm{O}_{4} @ \mathrm{AD}$ also acted as affinity support for the immobilization of antibody of PGE1(anti-PGE1), and the ECL signal of $\mathrm{S}_{2} \mathrm{O}_{8}{ }^{2-}$ would decline once anti-PGE1 recognized with PGE1. Upon the basis of different signal change, the concentration of PGE1 could be monitored through a simple method of label-free. And this proposed strategy has been successfully applied in serum samples for PGE1 and possessed significant potential application in the clinical diagnosis.

\section{Experimental section}

\section{Reagent}

Potassium persulfate was obtained from Sinopharm Chemical Reagent Co., Ltd. (China). 1-Adamantanecarboxylic acid was purchased from Aladdin Inc. (Shanghai, China). Human prostaglandin E1 (PGE1) standard, corresponding capture antibody $\left(\mathrm{Ab}_{1}\right)$ for human PGE1 ELISA kits were purchased from Lanhao biotech.Co., Ltd. (China). Glutaraldehyde and bovine serum albumin (BSA, 96-99\%) were purchased from Beijing Bioss Biology Technology Ltd. (China). Phosphate buffer solution (PBS) at various $\mathrm{pH}$ values was prepared by mixing $0.1 \mathrm{M} \mathrm{Na}_{2} \mathrm{HPO}_{4}$ and $0.1 \mathrm{M} \mathrm{NaH}_{2} \mathrm{PO}_{4}$, adjusted by $0.1 \mathrm{M} \mathrm{HCl}$ or $\mathrm{NaOH}$ under monitoring of PHS-3C exact digital $\mathrm{pH}$ metre (Shanghai, China).

\section{Apparatus}

Scanning electron microscopy (SEM, SU8000 instrument), Transmission electron microscopy (TEM, FEI F20 S-TWIN instrument), and Fourier transform infrared spectrometer( FTIR, Agilent Cary 660) were applied for the structural characterization of the resulting nanosheets. X-ray diffraction (XRD) patterns were recorded on a 
PANalytical X'Pert spectrometer using the Co K $\alpha$ radiation $(\lambda=1.78897 \AA)$, and the data were changed to $\mathrm{Cu} \mathrm{K} \alpha$ data.

Electrochemiluminescent measurements were carried out on BPCL Ultra-Weak Chemiluminescence Analyzer controlled by a personal computer with BPCL program (Institute of Biophysics, Chinese Academy of Sciences, Beijing, China) in conjunction with a CHI760 electrochemical analyzer (Shanghai Chenghua Instrument Co.,Shanghai, China). A conventional three-electrode system was formed with a platinum wire as auxiliary electrode, $\mathrm{Ag} / \mathrm{AgCl}$ as the reference electrode, and a glass carbon electrode as the working electrode during ECL detection.

\section{The synthesis of $\mathrm{NiCo}_{2} \mathrm{O}_{4}$}

Synthesis of ultrathin $\mathrm{NiCo}_{2} \mathrm{O}_{4}$ nanosheets with mesoporous structure was obtained according to the previously reported method [37]. In brief, $1 \mathrm{mmol}$ of $\mathrm{Ni}\left(\mathrm{NO}_{3}\right)_{2} \cdot 6 \mathrm{H}_{2} \mathrm{O}, \quad 2 \mathrm{mmol}$ of $\mathrm{Co}\left(\mathrm{NO}_{3}\right)_{2} \cdot 6 \mathrm{H}_{2} \mathrm{O}$ and 4.5 mmol of hexamethylenetetramine are dissolved in the solution, consisting of $20 \mathrm{~mL}$ ethanol and $40 \mathrm{~mL}$ deionized (DI) water, then transferred into $100 \mathrm{~mL}$ Teflon-lined. After that, the solution was stirred at $90{ }^{\circ} \mathrm{C}$ for $24 \mathrm{~h}$ by magnetic stirrer. After cooling to room temperature, the precipitates were collected by centrifugation and washed with DI water and ethanol for several times. The product was then dried in the blast oven at 60 ${ }^{\circ} \mathrm{C}$ for $12 \mathrm{~h}$. Finally, the product was annealed at $350{ }^{\circ} \mathrm{C}$ for $2 \mathrm{~h}$ in air in order to obtain mesoporous $\mathrm{NiCo}_{2} \mathrm{O}_{4}$ nanosheets .

\section{The Fabrication of the ECL Biosensor}

Prior to biosensor fabrication, the bare glassy carbon electrode (GCE) was 
polished to a mirror-shiny surface with $0.3 \mu \mathrm{m}$ alumina powder slurries, and sonicated with 1:1 (V:V) $\mathrm{HNO}_{3}$ solution, absolute ethanol and deionized water, respectively. The ECL biosensor was constructed as following steps: $1.0 \mathrm{~mL}$ of $1.0 \mathrm{mg} / \mathrm{mL}$ as-synthesized $\mathrm{NiCo}_{2} \mathrm{O}_{4}$ was mixed with $1.0 \mathrm{~mL}$ of $1.0 \%$ 3-aminopropyltriethyloxy silane (APTES) for $12 \mathrm{~h}$ with shake, then the functionalized product was collected and redispersed in $2.0 \mathrm{~mL}$ of deionized water and then was mixed with the EDC/NHS activated 1-adamantanecarboxylic acid (AD-COOH) for $2 \mathrm{~h}$ to form $\mathrm{AD}-\mathrm{COOH}$ decorated $\mathrm{NiCo}_{2} \mathrm{O}_{4}\left(\mathrm{NiCo}_{2} \mathrm{O}_{4} @ \mathrm{AD}\right)$ and the mixture was centrifuged and redispersed in $2.0 \mathrm{~mL}$ of deionized water. Following that, $3 \mu \mathrm{L}$ of $0.5 \mathrm{mg} / \mathrm{mL} \mathrm{NiCo}_{2} \mathrm{O}_{4} @ \mathrm{AD}$ was cast on the bare GCE surface and dried under an infrared lamp. After using $30 \mu \mathrm{L}$ of $2.0 \%$ glutaraldehyde solution to activate the amine group of $\mathrm{NiCo}_{2} \mathrm{O}_{4} @ \mathrm{AD}$, the resultant electrode was incubated with $30 \mu \mathrm{L}$ of anti-PGE1 for $40 \mathrm{~min}$, and the physically absorbed excess anti-PGE1 was rinsed with deionized water. Subsequently, the obtained electrode was incubated with $40 \mu \mathrm{L}$ of $1.0 \mathrm{wt} \%$ bovine serum albumin (BSA) solution for $1 \mathrm{~h}$ to block nonspecific bind sites. All the Above procedures were performed at $4{ }^{\circ} \mathrm{C}$. And the prepared electrode was stored at $4{ }^{\circ} \mathrm{C}$.

\section{ECL detection of PGE1}

To carry out the detection of PGE1, $30 \mu \mathrm{L}$ of different concentrations of PGE1 was added onto the above prepared electrode surface and incubated for $40 \mathrm{~min}$. Then a three-electrode system consisted of a platinum wire electrode as the auxiliary electrode, an $\mathrm{Ag} / \mathrm{AgCl}$ electrode as the reference electrode, and the prepared electrodes as the working electrodes was applied. And the obtained electrode was 
placed in $0.1 \mathrm{M}$ PBS solution ( $\mathrm{pH}$ 8.0) containing $0.1 \mathrm{M} \mathrm{K}_{2} \mathrm{~S}_{2} \mathrm{O}_{8}$ for ECL measurement by scanning the potential from 0.8 to $-1.8 \mathrm{~V}$ at the scan rate of $100 \mathrm{mV}$ $\mathrm{s}^{-1}$ with the voltage of photomultiplier tube (PMT) of $900 \mathrm{~V}$.

\section{Result and discussion}

\section{Characterizations of $\mathrm{NiCo}_{2} \mathrm{O}_{4}$ nanosheets and $\mathrm{NiCo}_{2} \mathrm{O}_{4} @ \mathrm{AD}$ nanocomposite}

Various characteristic techniques were carried out for the sake of gaining insight into the morphologies and structures of as-synthesized $\mathrm{NiCo}_{2} \mathrm{O}_{4}$ nanosheets. The scanning electron microscopy (SEM) images of the $\mathrm{NiCo}_{2} \mathrm{O}_{4}$ nanosheets were depicted in Figure.1A. It was shown clearly that the numerous nanosheets interconnected with each other were formed and the porous nature could be observed. The transmission electron microscope (TEM) images were used to further characterize the microstructure of the nanosheets, as shown in Figure 1B. It could be clearly observed that $\mathrm{NiCo}_{2} \mathrm{O}_{4}$ nanosheets were constructed by $\mathrm{NiCo}_{2} \mathrm{O}_{4}$ nanoparticle subunits interconnected to each other, leading to the formation of a large number of interparticle pores and this porous feature largely could increase the amount of electroactive sites. The inset of Figure 1B shown the high resolution transmission electron microscopy (HRTEM) image of $\mathrm{NiCo}_{2} \mathrm{O}_{4}$ nanosheets, which obviously revealed the clear lattice fringes of ca. $0.25 \mathrm{~nm}$, matching well with the (311) crystal plane of spinel $\mathrm{NiCo}_{2} \mathrm{O}_{4}$. In addition, the crystalline structure and phase purity of product was further studied by X-ray diffraction (XRD) (Figure 1C), the distinct characteristic peaks on wide-angle XRD patterns were observed at $2 \theta$ values of $19.3^{\circ}$,

$31.2^{\circ}, 36.8^{\circ}, 44.8^{\circ}, 55.8^{\circ}, 59.3^{\circ}$ and $65.2^{\circ}$, which could be indexed to the (111), 
(220), (311), (400), (422), (511), and (440) crystal planes of $\mathrm{NiCo}_{2} \mathrm{O}_{4}$ (JCPDS No. 20-0781), respectively. Moreover, the XRD patterns didn't reveal other impurity peaks, which suggested that the as-synthesized $\mathrm{NiCo}_{2} \mathrm{O}_{4}$ nanosheets possessed high purity. Furthermore, the $\mathrm{NiC}_{2} \mathrm{O}_{4}$-nanosheets exhibited broad diffraction peaks indicating the smaller crystallite size of this material.

The IR spectra were carried out to prove the successful preparation of the $\mathrm{NiCo}_{2} \mathrm{O}_{4} @ \mathrm{AD}$ nanocomposite (Figure $\mathrm{S} 1$ ). In the IR-spectral range of AD-COOH, there were absorption bands at $1511 \mathrm{~cm}^{-1}$ and $1666 \mathrm{~cm}^{-1}$, which were typical of $\mathrm{C}=\mathrm{C}$ of benzene skeleton vibration and $\mathrm{C}=\mathrm{O}$ of carboxyl stretching vibration (curve a). And there were no obvious absorption bands in the IR-spectral range of amino-modified $\mathrm{NiCo}_{2} \mathrm{O}_{4}$ between $1500 \mathrm{~cm}^{-1}$ and $3300 \mathrm{~cm}^{-1}$ (curve b). Furthermore, there were absorption bands at $1666 \mathrm{~cm}^{-1}$ and $3185 \mathrm{~cm}^{-1}$ appearing (curve c), which were $\mathrm{C}=\mathrm{O}$ and $\mathrm{N}-\mathrm{H}$ absorption peak of amide group successively, illustrating that the successful synthesis $\mathrm{NiCo}_{2} \mathrm{O}_{4} @ \mathrm{AD}$ nanocomposite.

\section{Electrocatalytic activity of the catalysts}

In order to investigate the catalytic performance of $\mathrm{NiCo}_{2} \mathrm{O}_{4} @ \mathrm{AD}$ toward the OER process, several corresponding electrochemical experiments were implemented. As shown in Figure 2A, no significant current was produced on AD modified electrode (curve b), indicating the AD possessed poor catalytic activity toward water oxidation. As expected, the $\mathrm{NiCo}_{2} \mathrm{O}_{4}$ modified electrode showed high current intensity and low onset potential for $\mathrm{O}_{2}$ evolution (curve c), which attributed to the excellent electrical conductivity and high porosity of ultrathin $\mathrm{NiCo}_{2} \mathrm{O}_{4}$ sheets that could 
facilitate the transportation of $\mathrm{O}_{2}$ and electrolyte and then improve OER activity. However, an exciting phenomenon could be observed on $\mathrm{NiCo}_{2} \mathrm{O}_{4} @ \mathrm{AD}$ modified electrode (curve d), the current intensity was much higher than that of $\mathrm{NiCo}_{2} \mathrm{O}_{4}$ modified electrode, while the onset potential was lower. These phenomena demonstrated that the $\mathrm{NiCo}_{2} \mathrm{O}_{4}$ functionalized with $\mathrm{AD}$ could largely improve the electrocatalytic activity toward OER ascribed to the synergistic effect between the ultrathin $\mathrm{NiCo}_{2} \mathrm{O}_{4}$ nanosheets with high porosity and excellent electrical conductivity and $\mathrm{AD}$ with large steric bulk and electron-donating abilities. In order to further validate that the $\mathrm{NiCo}_{2} \mathrm{O}_{4} @ A D$ could catalyze the OER process to yield $\mathrm{O}_{2}$, another electrochemical experiment of $\mathrm{CV}$ was carried out. As exhibited from Figure 2B, there was no obvious reduction peak could be observed from GCE (curve a) while an obvious reduction peak was observed from $\mathrm{NiCo}_{2} \mathrm{O}_{4} @ \mathrm{AD}$ modified electrode (curve b) after experiencing the OER process in the $0.1 \mathrm{M}$ deoxygenate $\mathrm{KOH}$ solution (eurve b), which further suggested that the $\mathrm{NiCo}_{2} \mathrm{O}_{4} @ \mathrm{AD}$ could expedite the OER process and generate $\mathrm{O}_{2}$.

\section{The ECL behavior and its mechanisms}

To further confirm the catalytic activity of $\mathrm{NiCo}_{2} \mathrm{O}_{4} @ \mathrm{AD}$, the ECL emission measurements were recorded. As shown in Figure 3A, bare GCE produced weak ECL in the detetion solution (curve a) due to the peroxydisulfate solution ECL. First of all, the $\mathrm{S}_{2} \mathrm{O}_{8}{ }^{2-}$ obtained an electron via electrode and turned to $\mathrm{SO}_{4}{ }^{--}$. The $\mathrm{O}_{2}$ was reduced to produce $\mathrm{HOO}^{\circ}$ which could react with the oxidant mediators of $\mathrm{SO}_{4}{ }^{--}$to yield the radiative deactivation of the singlet state oxygen $\left({ }_{1}\left(\mathrm{O}_{2}\right)_{2} *\right)$ and generate luminescence 
under cathode potential. And the possible mechanism of reaction was outlined as follows [9]:

$$
\begin{aligned}
& \mathrm{S}_{2} \mathrm{O}_{8}{ }^{2-}+\mathrm{e}^{-} \rightarrow \mathrm{SO}_{4}^{\cdot-}+\mathrm{SO}_{4}{ }^{2-} \\
& \mathrm{SO}_{4}{ }^{--}+\mathrm{H}_{2} \mathrm{O} \rightarrow \mathrm{HO}^{\bullet}+\mathrm{HSO}_{4}^{-} \\
& \mathrm{HO} \rightarrow \mathrm{HOO}^{-}+\mathrm{H}_{2} \mathrm{O} \\
& \mathrm{H}_{2} \mathrm{O} \stackrel{\mathrm{NiCo}_{2} \mathrm{O}_{4} @ \mathrm{AD}}{\longrightarrow} \mathrm{O}_{2}+4 \mathrm{H}^{+}+4 \mathrm{e}^{-} \\
& \mathrm{O}_{2}+\mathrm{H}_{2} \mathrm{O}+\mathrm{e}^{-} \rightarrow \mathrm{HOO}^{\cdot}+\mathrm{HO}^{-} \\
& \mathrm{SO}_{4}{ }^{--}+\mathrm{HOO}^{\cdot} \rightarrow \mathrm{HSO}_{4}^{-}+{ }^{1}\left(\mathrm{O}_{2}\right)_{2}{ }^{*}
\end{aligned}
$$

The ECL response increased after $\mathrm{NiCO}_{2} \mathrm{O}_{4}$ nanosheets modified on the bare GCE (curve b), which was attributed to the ultrathin $\mathrm{NiCo}_{2} \mathrm{O}_{4}$ nanosheets of the high porosity would largely increase the amount of electro-active sites and accelerate the electron transfer in ECL reaction. The ECL responses of $\mathrm{NiCo}_{2} \mathrm{O}_{4} @ \mathrm{AD}$ modified electrode (curve c) had a significant improvement compared to the bare GCE and $\mathrm{NiCo}_{2} \mathrm{O}_{4}$ modified electrode, because of the electron-donating ability of AD tended to increase the ECL intensity. In addition, the synergistic effect in bifunctional catalyst could further improve the performance in catalysis of OER process where the $\mathrm{O}_{2}$ was generated[35]. However, the ECL intensity decreased gradually when the resulting electrode was incubated with anti-PGE1 (curve d) and PGE1 (curve e) successively, which ascribed to the anti-PGE1, PGE1 acted as mass-transfer blocking layer could hamper the diffusion of the ECL reagent toward electrode surface and hindered the electron transfer. Namely, these phenomena validated the immunosensor was successfully developed. 


\section{Construction and characterization of ECL biosensor}

As an effective method to monitor the assembly of the immunosensor and the features of the modified electrode surface[33,34], the electrochemical impedance spectroscopy (EIS) was employed to further characterize the stepwise fabrication process of the ECL biosensor by utilizing the equimolar $\left[\mathrm{Fe}(\mathrm{CN})_{6}\right]^{3-14-}$ as a redox probe. The impedance spectra are composed of a semicircle portion and a linear portion, and the semicircle diameter at higher frequencies assigned to the electron-transfer resistance (Ret) while the linear part at lower frequencies corresponds to the diffusion process. As shown in Figure 3B, before the modification, the bare GCE displayed a small semicircles (curve a). However, the Ret decreased when the $\mathrm{NiCo}_{2} \mathrm{O}_{4}$ was modified on $\mathrm{GCE}$ (curve b), which was attributed to the ultrathin $\mathrm{NiCo}_{2} \mathrm{O}_{4}$ nanosheets possessing excellent electronic conductivity. And obvious further decreasing of electron-transfer resistance was obtained from the $\mathrm{NiCo}_{2} \mathrm{O}_{4} @ \mathrm{AD}$ modified electrode (curve c), attributing to the synergistic effect between the ultrathin $\mathrm{NiCo}_{2} \mathrm{O}_{4}$ nanosheets with high porosity and $\mathrm{AD}$ with large steric bulk and electron-donating abilities. After the resultant electrode was incubated with anti-PGE1 (curve d) and PGE1 (curve e) successively, the electron-transfer resistance gradually increased attributed to that the anti-PGE1 and PGE1 acted as mass-transfer blocking layer which could hinder the electron transport and prevent the diffusion of the redox probe toward the electrode surface [36]. These results further validated that the biosensor was effectively and successfully fabricated.

\section{Optimization of experiment conditions}


In order to obtain favorable detection results, several optimization experiments were carried out concerning at the influence factors. The concentration of $\mathrm{NiCo}_{2} \mathrm{O}_{4} @ \mathrm{AD}$ is a very important parameter on the biosensor performance due to that $\mathrm{NiCo}_{2} \mathrm{O}_{4} @ \mathrm{AD}$ acted as affinity support of biosensor and enhancer of ECL performance. As shown in Figure 4A, the ECL intensity increased gradually with the concentration of $\mathrm{NiCo}_{2} \mathrm{O}_{4} @ \mathrm{AD}$ increasing from $0.5 \mathrm{mg} / \mathrm{ml}$ to $1.5 \mathrm{mg} / \mathrm{ml}$, and decreased significantly when the concentration over $1.5 \mathrm{mg} / \mathrm{ml}$. The phenomena could be attributed to the moderate amount of $\mathrm{NiCo}_{2} \mathrm{O}_{4} @ \mathrm{AD}$ could facilitate the OER process and yield more dissolved oxygen on electrode surface, but excessive $\mathrm{NiCo}_{2} \mathrm{O}_{4} @ \mathrm{AD}$ on electrode surface would enhance the steric hindrance and hinder the diffusion of the ECL reagent toward electrode surface. Therefore, $1.5 \mathrm{mg} / \mathrm{ml} \mathrm{was}$ chosen as optimal concentration for the fabrication of ECL biosensor. Furthermore, $\mathrm{pH}$ value of PBS was evaluated to get a predominant ECL performance for the proposed biosensor. The ECL signal increased with the increasing of $\mathrm{pH}$ value from 6.5 to 8.5 (Figure 4B), and this phenomenon might ascribe to the OER process uneasily take place at low $\mathrm{pH}$. Therefore, the optimal $\mathrm{pH}$ value of PBS solution for the ECL system was 8.0 taking account of the bioactivity. In addition, the ECL signal of the biosensor decreased obviously with the incubation time of anti-PGE1, but tended to level off after $40 \mathrm{~min}$ (Figure 4C), which suggested the saturation of anti-PGE1 on the immunosensor surface. Accordingly, 40 min was chosen as the optimal incubation time. In addition, the incubation time of PGE1 was optimized, and Figure 4D indicated the ECL signal became a steady value after the incubation time of PGE1 was 40 min, which was then selected as the optimal incubation time for the following research.

\section{Analytical Performance of the Biosensor}


Under the optimal detection conditions, ECL measurements were carried out to quantitatively assess the response range and detection limit of the biosensor for PGE1. As showed in Figure 5A, the elevated concentration of the PGE1 from $0.1 \mathrm{fg} / \mathrm{ml}$ to 1 $\mathrm{ng} / \mathrm{ml}$ resulted in continuing decline in the ECL intensity. By analyzing the ECL intensity ( I) with the concentrations of PGE1, it was found that the "I " exhibited a good linear negative relationship with the logarithm of PGE1 concentration in the range from $0.1 \mathrm{fg} / \mathrm{ml}$ to $1 \mathrm{ng} / \mathrm{ml}$, as displayed in Figure 5B. The corresponding linear equation was $\mathrm{I}=1165.17-115.17 \log \mathrm{c}$ with the correlation coefficient of $\mathrm{R}^{2}=0.9989$. Furthermore, the proposed immunosensor was more sensitive than other different test platforms of different cardiac biomarkers. (Table S1). Accordingly, this proposed biosensor displayed a wide linear response range and high sensitivity in the detection of PGE1. The result indicated that the proposed biosensor possessed excellent potential for accurate detection of PGE1.

Stability, another essential performance of the biosensor, was assessed under consecutive cyclic potential scans when the biosensor was incubated with $1 \mathrm{fg} / \mathrm{ml}$ PGE1. As depicted in Figure 5C, the proposed sensing platform possessed a superior stability with relative standard deviations (RSD) of $0.6 \%$ of ECL peaks in 10 cycles during the cyclic potential scanning between 0.8 and $-1.8 \mathrm{~V}$.

To further evaluate the selectivity and specificity of the present biosensor, some correlative proteins such as IL-6, CEA, AFP, BSA were exploited as interfering substance. The ECL emission measurements were carried out under same experimental condition after incubating with PGE1, IL-6, CEA, AFP, BSA at a same concentration of $1 \mathrm{pg} / \mathrm{ml}$. As shown in Figure 5D, there were no significant 
differences appear in the ECL intensity excepted incubating with PGE1, which indicated the selectivity and specificity of the biosensor were acceptable.

To evaluate the applicability and reliability of the proposed ECL immunosensor, healthy human serum samples were detected, and the recovery experiments of PGE1 in human serum were performed by standard addition methods, as shown in Table 1, the recoveries of PGE1 were in the range of 93.5- $115 \%$, indicating the present immunosensor possessed the reliability to detect the PGE1 in real biological samples.

\section{Conclusions}

In summary, a bifunctional catalyst $\mathrm{NiCO}_{2} \mathrm{O}_{4} @ \mathrm{AD}$ was utilized to fabricate a novel ECL immunosensor for ultrasensitive detection of PGE1, a cardiac biomarker. In the light of $\mathrm{NiCo}_{2} \mathrm{O}_{4} @ \mathrm{AD}$ combining the merits inherited from $\mathrm{NiCo}_{2} \mathrm{O}_{4}$ such as ultrathin feature, high porosity, large surface area, and excellent electrical conductivity, and the merits inherited from $\mathrm{AD}$ with large steric bulk and electron-donating abilities, it was not only exploited as affinity support for anti-PGE1, but also could act as electrocatalyst for OER and facilitate the $\mathrm{O}_{2}$ evolution. Thus the ECL intensity of $\mathrm{S}_{2} \mathrm{O}_{8}{ }^{2-}$ was enhanced with the increasing of $\mathrm{O}_{2}$, and once the anti-PGE1 recognized with PGE1, the ECL signal would suffer decline. On the basis of the ECL signal change, the proposed ECL immunosensor could achieve the ultrasensitive determination for PGE1 with excellent sensitivity, stability and selectivity via label-free method. Furthermore, this proposed immunosensor holds great potential for further application in other fields.

\section{Acknowledgments}

This project was financially supported by the NSFC $(21205016,21575024)$, National Science Foundation of Fujian Province (2016J06003, 2016J05026), Education Department of Fujian Province (JA14071, JB14036, JA13068) and Foundation of 
Fuzhou Science and Technology Bureau (2015-S-160, 2015-G-72) and New Century Talent Project of Fujian Province.

\section{Reference}

[1] W. T. Fang, H. J. Li, L. S. Zhou. Protective effects of prostaglandin E-1 on human umbilical vein endothelial cell injury induced by hydrogen peroxide, Acta Pharmacologica Sinica, 31(2010) 485.

[2] S. M. Davidson, D. Cabral-Lilly, F. P. Maurio, J. C. Franklin, S. R. Minchey, P. L. Ahl, A. S. Janoff, Biochimica et biophysica acta, 1327(1997) 97.

[3] A. Aykanat, T. Yavuz, E. Ozalkaya, S. Topcuoglu, F. Ovali, G. Karatekin, Long-Term Prostaglandin E1 Infusion for Newborns with Critical Congenital Heart Disease, Pediatric Cardiology, 37(2016)131.

[4] H. Z. Pan, J. H. Liu, Y. Y. Dong, M. Sima, P. Kopeckova, M. L. Brandi, J. Kopecek, Release of Prostaglandin E1 from N -(2-Hydroxypropyl) methacrylamide Copolymer Conjugates by Bone Cells, Macromolecular Bioscience, 8 (2008) 599.

[5] D. Moertl, R. Berger, M. Huelsmann, A. Bojic, R. Pacher, Short-term effects of levosimendan and prostaglandin E1 on hemodynamic parameters and B-type natriuretic peptide levels in patients with decompensated chronic heart failure, The European Journal of Heart Failure, 7 (2005) 1156.

[6] H. Dai, G. F. Xu, S. P. Zhang, Z. S. Hong, Y. Y. Lin, A ratiometric biosensor for metallothionein based on a dual heterogeneous electrochemiluminescent response from a $\mathrm{TiO}_{2}$ mesocrystalline interface, Chem. Commun., 51(2015) 7697.

[7] A. Y. Chen, G. F. Gui, Y. Zhuo, Y. Q. Chai, Y. Xiang, R. Yuan, Signal-off Electrochemiluminescence Biosensor Based on Phi29 DNA Polymerase Mediated 
Strand Displacement Amplification for MicroRNA Detection, Anal. Chem., 87 (2015) 6328.

[8] X. J. Li, X. Y. Zhang, H. M. Ma, D. Wu, Y. Zhang, B. Du, Q. Wei, Cathodic electrochemiluminescence immunosensor based on nanocomposites of semiconductor carboxylated $\mathrm{g}-\mathrm{C}_{3} \mathrm{~N}_{4}$ and graphene for the ultrasensitive detection of squamous cell carcinoma antigen, Biosensors and Bioelectronics, 55 (2014) 330.

[9] H. Niu, R. Yuan, Y. Q. Chai, L. Mao, H. J. Liu, Y. L. Cao. Highly amplified electrochemiluminescence of peroxydisulfate using bienzyme functionalized palladium nanoparticles as labels for ultrasensitive immunoassay, Biosensors and Bioelectronics, 39 (2013) 296.

[10] H. J. Wang, L. J. Bai, Y. Q. Chai, R. Yuan, Synthesis of Multi-Fullerenes Encapsulated Palladium Nanocage, and Its Application in Electrochemiluminescence Immunosensors for the Detection of Streptococcus suis Serotype 2, Small, 10 (2014) 1857.

[11] W. Y. Liu, H. M. Yang, S. G. Ge, L. Shen, J. H. Yu, M. Yan, J. D. Huang Application of bimetallic PtPd alloy decorated graphene in peroxydisulfate electrochemiluminescence aptasensor based on Ag dendrites decorated indium tin oxide device, Sensors And Actuators B-Chemical, 209 (2015) 32.

[12] W. Sun, Y. Song, X. Q. Gong, L. M. Cao, J. Yang, Hollandite Structure $\mathrm{Kx} \approx 0.25 \mathrm{IrO}_{2}$ Catalyst with Highly Efficient Oxygen Evolution Reaction, ACS Appl. Mater. Interfaces, 8 (2016) 820.

[13] H. S. Ahn, A. J. Bard, Surface Interrogation Scanning Electrochemical Microscopy of $\mathrm{Ni}_{1}-\mathrm{xFexOOH}(0<\mathrm{x}<0.27)$ Oxygen Evolving Catalyst: Kinetics of the "fast" Iron Sites, J. Am. Chem. Soc., 138 (2016) 313. 
[14] W. N. Yan, X. C. Cao, K. Ke, J. H. Tian, C. Jin, R. Z. Yang, One-pot synthesis of monodispersed porous $\mathrm{CoFe}_{2} \mathrm{O}_{4}$ nanospheres on graphene as an efficient electrocatalyst for oxygen reduction and evolution reactions, RSC Adv., 6 (2016) 307. [15] Y. M. Li, H. Y. He, W. Fu, C. Z. Mu, X. Z. Tang, Z. Liu, D. Z. Chi, X. Hu, In-grown structure of NiFe mixed metal oxides and CNT hybrid catalysts for oxygen evolution reaction, Chem. Commun., 52 (2016)1439.

[16] H. Dai, L. S. Gong, S. P. Zhang, G. F. Xu, Y. L. Li, Z. S. Hong, Y. Y. Lin, All-in-one bioprobe devised with hierarchical-ordered magnetic $\mathrm{NiCo}_{2} \mathrm{O}_{4}$ superstructure for ultrasensitive dual-readout immunosensor for logic diagnosis of tumor marker, Biosensors and Bioelectronics, 77 (2016) 928-935.

[17] Y. P. Huang, Y. E. Miao, H. Y. Lu, T. X. Liu, Hierarchical $\mathrm{ZnCo}_{2} \mathrm{O}_{4} @ \mathrm{NiCo}_{2} \mathrm{O}_{4}$ Core-Sheath Nanowires: Bifunctionality towards High-Performance Supercapacitors and the Oxygen-Reduction Reaction, Chem.Eur.J., 21 (2015) 10100.

[18] H. Jiang, J. Ma, C. Li, Hierarchical Porous $\mathrm{NiCo}_{2} \mathrm{O}_{4}$ Nanowires for High-Rate Supercapacitors, Chem. Commun., 48 (2012) 4465.

[19] Y. G. Li, P. Hasin, Y. Y. Wu, Nanowire Arrays for Electrocatalytic Oxygen Evolution, Adv. Mater., 22 (2010) 1926.

[20] L. Li, Y. Cheah, Y. Ko, P. Teh, G. Wee, C. Wong, S. Peng, M. Srinivasan, The Facile Synthesis of Hierarchical Porous Flower-like $\mathrm{NiCo}_{2} \mathrm{O}_{4}$ with Superior Lithium Storage Properties, J. Mater. Chem. A, 1 (2013) 10935.

[21] R. Ding, L. Qi, M. Jia, H. Wang, Porous $\mathrm{NiCo}_{2} \mathrm{O}_{4}$ nanostructures as bi-functional electrocatalysts for $\mathrm{CH}_{3} \mathrm{OH}$ oxidation reaction and $\mathrm{H}_{2} \mathrm{O}_{2}$ reduction reaction. Electrochimica Acta, 113 (2013) 290. 
[22] M. Prabu, K. Ketpang, S. Shanmugam. Hierarchical nanostructured $\mathrm{NiCo}_{2} \mathrm{O}_{4}$ as an efficient bifunctional non-precious metal catalyst for rechargeable zinc-air batteries. Nanoscale, 6(2014) 3173.

[23] G. Q. Zhang, X. W. (David) Lou, Controlled Growth of $\mathrm{NiCo}_{2} \mathrm{O}_{4}$ Nanorods and Ultrathin Nanosheets on Carbon Nanofibers for High-performance Supercapacitors, Scientific Reports, 3 (2013) 1470.

[24] R. Liu, C. Malotki, L. Arnold, N. Koshino, H. Higashimura, M. Baumgarten, K. Müllen, Triangular Trinuclear Metal- $\mathrm{N}_{4}$ Complexes with High Electrocatalytic Activity for Oxygen Reduction, J. Am. Chem. Soc., 133 (2011) 10372.

[25] R. Chen, H. Y. Wang, J. Miao, H. Yang, B. Liu, A flexible high-performance oxygen evolution electrode with three-dimensional $\mathrm{NiCo}_{2} \mathrm{O}_{4}$ core-shell nanowires, Nano Energy, 11 (2015) 333.

[26] H. Zhang, H. Qiao, H. Wang, N. Zhou, J. Chen, Y. Tang, J. Li, C. Huang, Nickel Cobalt Oxide/carbon Nanotubes Hybrid as a High-performance Electrocatalyst for Metal/air Battery, Nanoscale, 6 (2014) 10235.

[27] Y. He, L. Xu, Y. Zhai, A. Li, X. Chen, A hexangular ring-core $\mathrm{NiCo}_{2} \mathrm{O}_{4}$ porous nanosheet/NiO nanoparticle composite as an advanced anode material for LIBs and catalyst for CO oxidation applications, Chem. Commun., 51 (2015) 14768.

[28] X. J. Bo, Y. F. Zhang, M. Li, A. Nsabimana, L. P. Guo, $\mathrm{NiCo}_{2} \mathrm{O}_{4}$ spinel/ordered mesoporous carbons as noble-metal free electrocatalysts for oxygen reduction reaction and the influence of structure of catalyst support on the electrochemical activity of $\mathrm{NiCO}_{2} \mathrm{O}_{4}$, Journal Of Power Sources, 288 (2015) 1.

[29] X. J. Lin, J. M. Su, L. Y. Li, A. S.Yu, Hierarchical porous $\mathrm{NiCo}_{2} \mathrm{O}_{4} @ \mathrm{Ni}$ as carbon-free electrodes for Lithium-oxygen batteries, Electrochimica Acta, 168 (2015) 292. 
[30] K. A. Agnew-Francis, C. M. Williams. Catalysts Containing the Adamantane Scaffold, Advanced Synthesis \& Catalysis, 358(2016) 675.

[31] J. Deng, X. Y. Liu, S. Q. Zhang, C. Cheng, C. X. Nie, C. S. Zhao, Versatile and Rapid Postfunctionalization from Cyclodextrin Modified Host Polymeric Membrane Substrate, Langmuir, 31 (2015) 9665.

[32] M. Holzinger, L. Bouffier, R. Villalonga, S. Cosnier, Adamantane/beta-cyclodextrin affinity biosensors based on single-walled carbon nanotubes, Biosensors and Bioelectronics, 24 (2009) 1128.

[33] C.W. Tsai, K. H. Wu, C. C. Yang, G. P. Wang. Adamantane-based epoxy resin and siloxane-modified adamantane-based epoxy resin: Characterization of thermal, dielectric and optical properties, Reactive \& Functional Polymers, 91 (2015)11.

[34] X. Wei, C. Xiao, K. Wang and Y. Tu, A nano-TiO supported AuAg alloy nanocluster functionalized electrode for sensitizing the electrochemiluminescent analysis, J. Electroanal. Chem., 702 (2013)37.

[35] S. Chen, S. Z. Qiao, Hierarchically Porous Nitrogen-Doped Graphene- $\mathrm{NiCo}_{2} \mathrm{O}_{4}$ Hybrid Paper as an Advanced Electrocatalytic Water-Splitting Material. Acs Nano, $7(2013) 10190$.

[36] Q. R. Zhang, H. Dai, Y. L. Li, S. P. Zhang ,G. F. Xu, S. H. Chen, Z. S. Hong, Y. Y. Lin, Ratiometric Electrochemiluminescent Immunoassay for Tumor Marker Regulated by Mesocrystals and Biomimetic Catalyst, Electrochimica Acta , 196 (2016) 565. 
[37] K. Q. Zhou, Z. S. Hong, C. B. Xie, H. Dai, Z. G. Huang, Mesoporous $\mathrm{NiCo}_{2} \mathrm{O}_{4}$ nanosheets with enhance sodium ion storage properties, Journal of Alloys and Compounds, 651 (2015) 24-28.

[38] J. Du, G. Zhou, H. M. Zhang, C. Cheng, J. M. Ma, W. F. Wei, L. B. Chen, T. H.Wang, Ultrathin Porous $\mathrm{NiCo}_{2} \mathrm{O}_{4}$ Nanosheet Arrays on Flexible Carbon Fabric for High-Performance Supercapacitors, ACS Appl. Mater. Interfaces, 5 (2013)7405-7409. 
Table 1. Determination of PGE1 added in normal human serum with the proposed immunosensor. $(\mathrm{n}=3)$

\begin{tabular}{cccc}
\hline Sample number & Added $(\mathrm{pg} / \mathrm{ml})$ & Found $(\mathrm{pg} / \mathrm{ml})$ & Recovery $(\%)$ \\
\hline 1 & 100 & $93.50 \pm 0.35$ & $93.50 \%$ \\
2 & 50 & $50.85 \pm 0.57$ & $101.7 \%$ \\
4 & 1 & $1.092 \pm 0.052$ & $109.2 \%$ \\
\hline
\end{tabular}

$\mathrm{n}$ is the repetitive measurements number. 
Figure 1
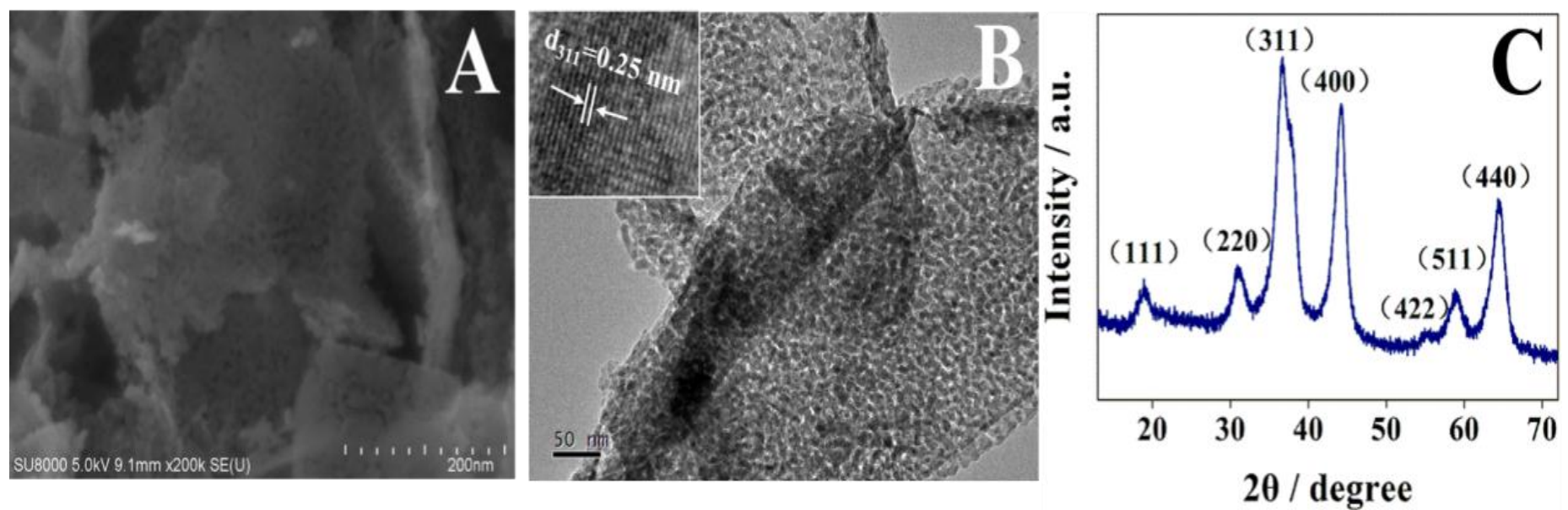

Figure 1. SEM images (A), TEM images (B) and XRD pattern (C) of prepared $\mathrm{NiCo}_{2} \mathrm{O}_{4}$ nanosheets. The inset in (B) is a HRTEM images. 
Figure 2
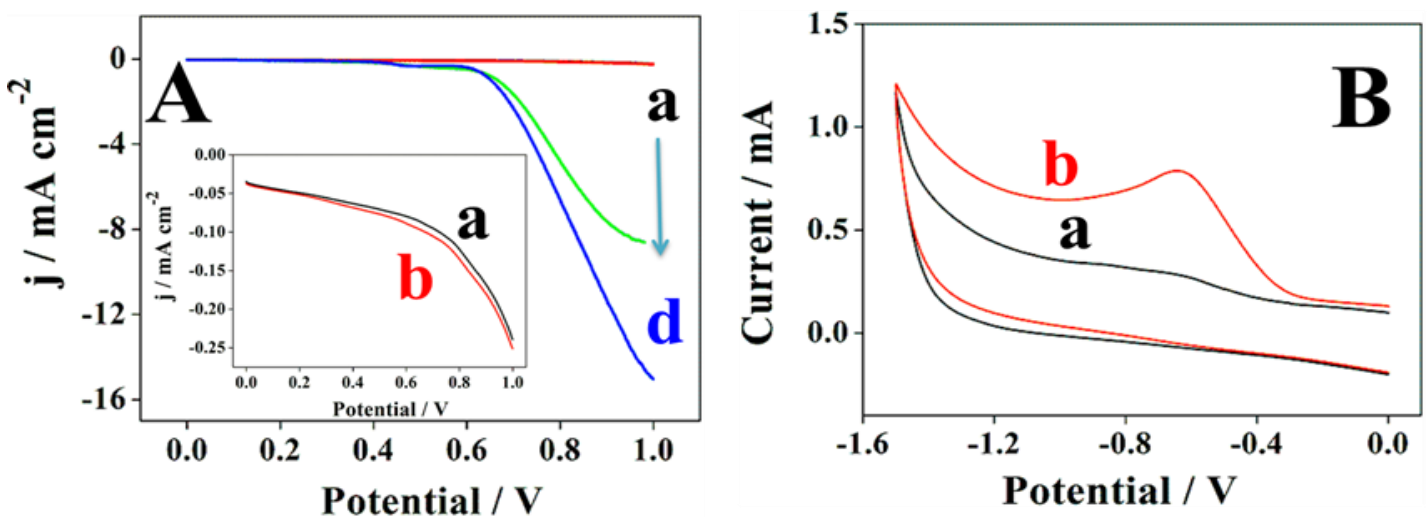

Figure 2. (A) polarization curves of GCE (a), GCE/AD (b), GCE/ $\mathrm{NiCo}_{2} \mathrm{O}_{4}$ (c), GCE/ $\mathrm{NiCo}_{2} \mathrm{O}_{4} @ \mathrm{AD}(\mathrm{d})$ in $0.1 \mathrm{M} \mathrm{KOH}$ solution at a scan rate of $20 \mathrm{mV} / \mathrm{s}$ (vs. $\mathrm{Ag} / \mathrm{AgCl}$ ), inset: the enlarged drawing of curve a and curve b. (B) CV curves on a GCE in $0.1 \mathrm{M}$ deoxygenate $\mathrm{KOH}$ solution (a) and $\mathrm{NiCo}_{2} \mathrm{O}_{4} @ \mathrm{AD}$ modified electrode (b) after an OER process in $0.1 \mathrm{M}$ deoxygenate $\mathrm{KOH}$ solution. 
Figure 3
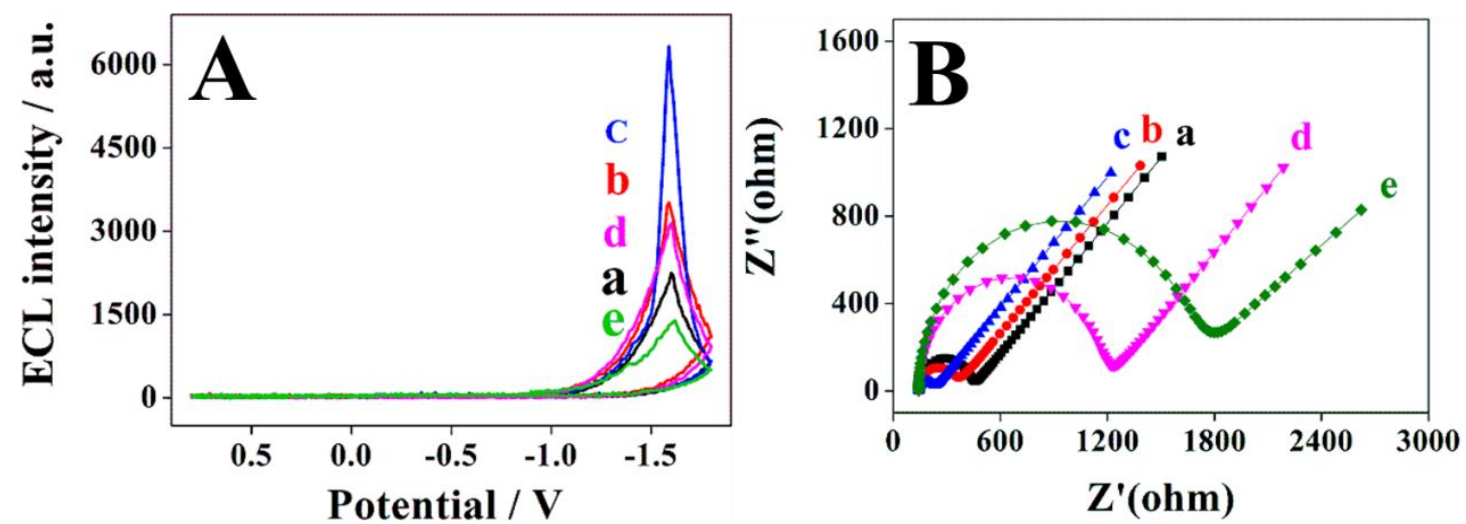

Figure 3. ECL intensity profiles (A) and Nyquist diagrams (B) of different electrodes, GCE (a), $\mathrm{NiCo}_{2} \mathrm{O}_{4} / \mathrm{GCE}$ (b), $\mathrm{NiCo}_{2} \mathrm{O}_{4} @ \mathrm{AD} / \mathrm{GCE}$ (c), anti-PGE1/NiCo $\mathrm{O}_{4} @ \mathrm{AD} / \mathrm{GCE}$ (d), PGE1/BSA/anti-PGE1/NiCo $2 \mathrm{O}_{4} @ \mathrm{AD} / \mathrm{GCE}$ (e). ECL intensity profiles tracked in $0.1 \mathrm{M}$ PBS buffer saline ( $\mathrm{pH}$ 8.0) containing $0.1 \mathrm{M} \mathrm{K}_{2} \mathrm{~S}_{2} \mathrm{O}_{8}$ and Nyquist diagrams tracked in $0.1 \mathrm{M} \mathrm{KCl}$ containing $5 \mathrm{mM} \mathrm{Fe}(\mathrm{CN}) 6^{3-/ 4-}$. 
Figure 4
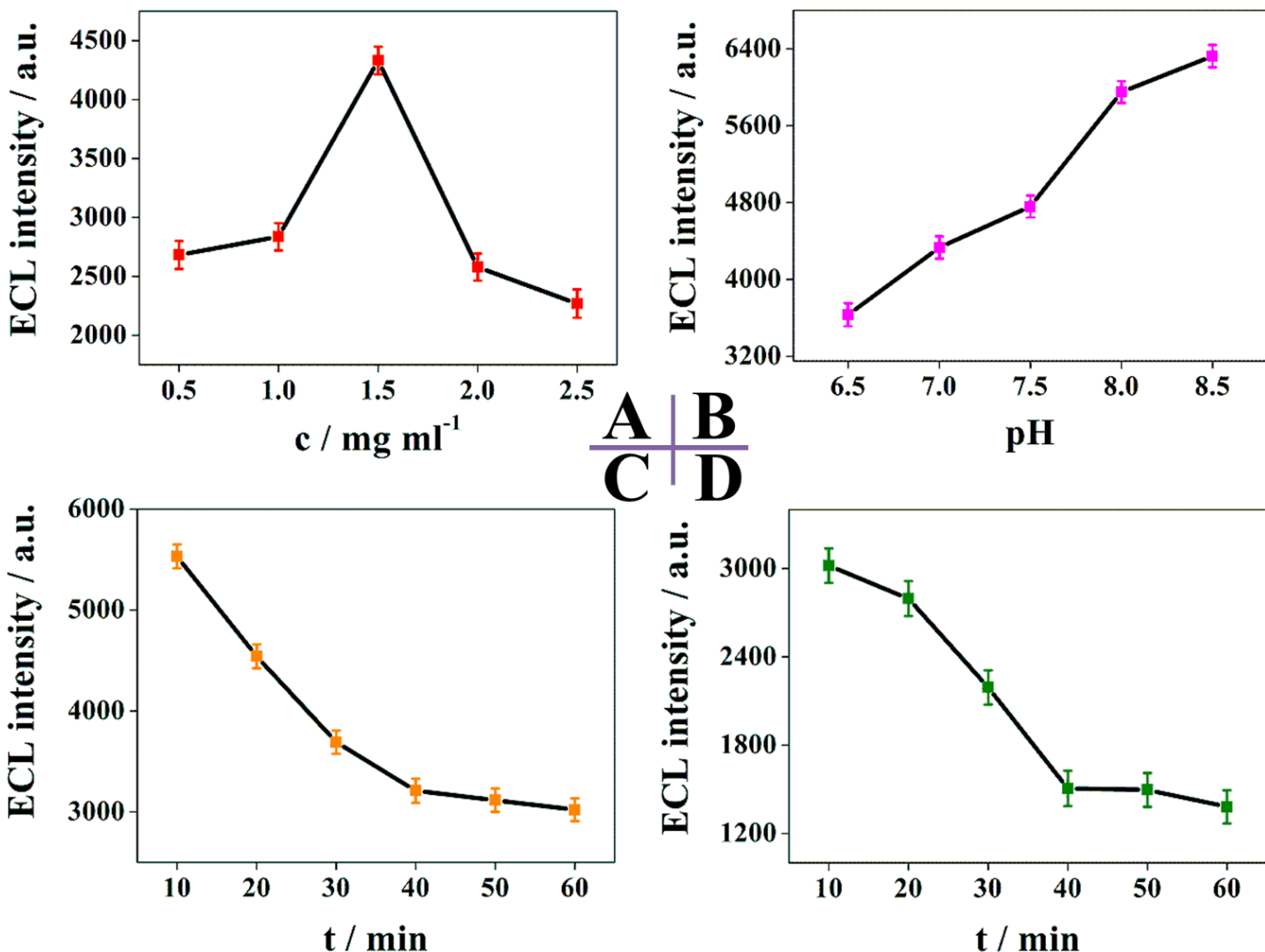

\begin{tabular}{l|l}
$\mathbf{A}$ & $\mathbf{B}$ \\
\hline $\mathbf{C}$ & $\mathbf{D}$
\end{tabular}

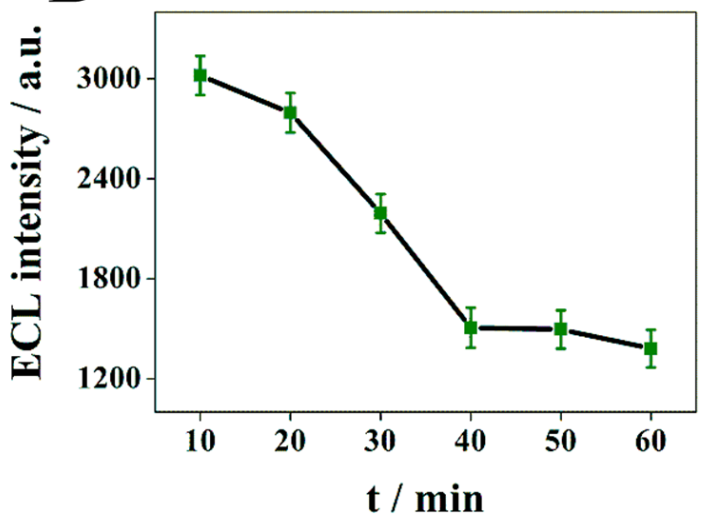

Figure 4. Effects of (A) the concentration of $\mathrm{NiCo}_{2} \mathrm{O}_{4} @ \mathrm{AD},(\mathrm{B}) \mathrm{pH}$ value, incubation time of anti-PGE1 (C) and PGE1 (D) on the ECL response of biosensor in 0.1 M PBS buffer saline containing $0.1 \mathrm{M} \mathrm{K}_{2} \mathrm{~S}_{2} \mathrm{O}_{8}$. 
Figure 5
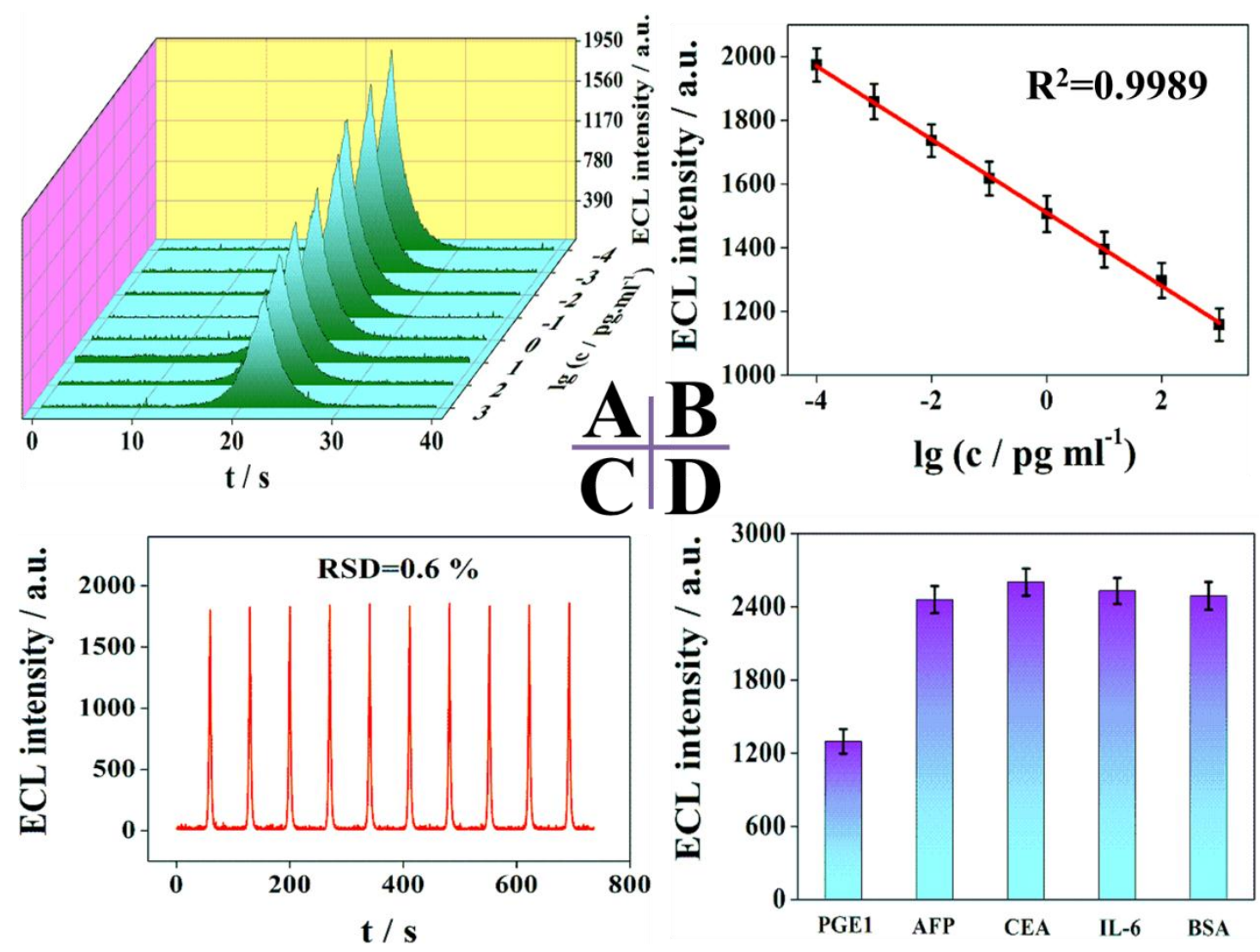

Figure 5. (A) ECL responses of immunosensor and (B) Calibration plot of the ECL intensity with different concentrations of PGE1 from $0.1 \mathrm{fg} / \mathrm{ml}$ to $1.0 \mathrm{ng} / \mathrm{ml}$. (C) The stability of the proposed ECL immunosensor under consecutive cyclic potential scans for 10 cycles. (D) The selective of the proposed ECL immunosensor in 0.1 M PBS ( $\mathrm{pH} 8.0$ ) containing $0.1 \mathrm{M} \mathrm{S}_{2} \mathrm{O}_{8}{ }^{2-}$. 